\title{
A RAZÃO NEGRA E O PROJETO ROMÂNTICO: dupla face do romance Úrsula (1859), de Maria Firmina dos Reis
}

Luiz Henrique Silva de Oliveira

(CEFET-MG)

https://orcid.org/0000-0003-1287-5317

\section{RESUMO}

Este estudo pretende analisar o romance Úrsula (1859), de Maria Firmina dos Reis, a partir do conceito de "razão negra", formulado por Achille Mbembe (2014), em contraste com a estética romântica que também ampara o livro da autora brasileira. E, além disso, objetiva-se discutir como este conceito de Mbembe ajuda a compreender a representação do negro realizada pelo texto firminiano. Para Mbembe, a "razão negra" liga-se à fabricação das imagens do saber e do sujeito afrodescendente. A hipótese deste ensaio é que a "razão negra" opera como dispositivo responsável por potencializar a compreensão de imagens de afrodescendentes no romance Úrsula, tais como exemplificadas por meio das trajetórias de Túlio, Mãe Susana e Antero. Se, por um lado, o livro em questão opta por seguir as linhas gerais do romantismo brasileiro, ao discutir a configuração da nação e a escravidão, por outro lado, ele o faz a partir dos paradigmas identitários pautados pela "razão negra", ou seja, o negro como sujeito das ações e do discurso.

PALAVRAS-CHAVE: razão negra; romantismo; Úrsula; Maria Firmina dos Reis. 


\section{BLACK REASON AND THE ROMANTIC PROJECT: double face of the novel Úrsula (1859), by Maria Firmina dos Reis}

\section{ABSTRACT}

This study intends to analyze the novel Úrsula (1859), by Maria Firmina dos Reis, based on the concept of «black reason» formulated by Achille Mbembe (2014), in contrast to the romantic aesthetic that also supports the author s book Brazilian. And, in addition, it aims to discuss how this concept of Mbembe helps to understand the representation of the black people realized by Firmina's text. For Mbembe, «black reason» is linked to the fabrication of images of knowledge and the afro-descendant subject. The hypothesis of this essay is that «black reason» operates as a device responsible for enhancing the understanding of afro-descendant images in the novel Ursula, as exemplified by the trajectories of Túlio, Mãe Susana and Antero. If, on the one hand, the book in question chooses to follow the general lines of Brazilian romanticism, when discussing the configuration of the nation and slavery, on the other hand it does so from the paradigms of identity ruled by "black reason", the black people as subject of actions and discourse.

KEYWORDS: black reason; romanticism; Úrsula; Maria Firmina dos Reis.

\section{Introdução}

Maria Firmina dos Reis nasceu em 11/10/1825 na cidade de São Luís (MA). É filha de João Pedro Esteves e Leonor Felipe dos Reis. Mulata, conviveu em um contexto assinalado pela escravidão e suas consequências, tais como a segregação racial, social e de gênero. Aos cinco anos, mudou-se para a casa de uma tia materna, situada na vila de São José de Guimarães, no município de Viamão. De acordo com Mott (1988), o convívio nesse espaço foi determinante para a formação intelectual e 
cidadã de Firmina. Já na interpretação de Luiza Lobo (1993), naquele local, a futura escritora teria obtido apoio intelectual do também escritor e gramático Sotero dos Reis, primo dela por parte de mãe. Maria Firmina exerceu o magistério durante significativa parte de sua vida, a ponto de receber o título de Mestra Régia, concedido aos detentores de notáveis saberes acadêmicos. Foi em 1847, com vinte e dois anos, que Firmina foi aprovada em concurso público para a Cadeira de Instrução Primária na cidade de Guimarães-MA, conforme registra seu biógrafo, Nascimento Morais Filho (1975).

Segundo Zahidé Muzart (1999, p. 164), "Maria Firmina dos Reis colaborou assiduamente com vários jornais literários, tais como Verdadeira marmota, Semanário maranhense, O domingo, O país, Pacotilha, Federalista e outros". As publicações em tais periódicos envolveram poesia, ficção, crônicas, enigmas e charadas. Do ponto de vista da prosa, a autora publicou dois romances e um conto. O livro de maior repercussão foi Úrsula (1859). Firmina também publicou Gupeva, obra de temática indianista, seguindo o arquivo temático romântico. Esta obra ocupou as páginas do jornal $O$ jardim das maranhenses de 1861 a 1862; em seguida, foi republicada pelo jornal Porto livre, em 1863, e, finalmente, nova versão saiu pelo Echo da juventude, em 1865. A escritora ainda levou ao público o conto "A escrava", por meio do terceiro número da Revista Maranhense, em novembro de 1887. Quanto à poesia, a artista escreveu Cantos à beira mar (1871), livro publicado pela Typografia do Paiz, provavelmente com recursos próprios. Maria Firmina dos Reis faleceu em 1917, pobre e cega, no município de Guimarães-MA.

É válido salientar que todos esses feitos não foram suficientes para o devido reconhecimento de Firmina na cena cultural brasileira. Conforme assinala Eduardo de Assis Duarte (apud REIS, 2004, p. 273), "uma espessa cortina de silêncio envolveu a autora ao longo de mais de um século". E ele tem razão, pois os pioneiros na escrita da história da literatura brasileira, por exemplo, como Sílvio Romero e José Veríssimo, não reconhecem Firmina como escritora, lamentável fato também notado em trabalhos de outros estudiosos, como Afrânio Coutinho, Alfredo Bosi, Antonio Candido, Nelson Werneck Sodré e tantos outros.

Arrisco dizer que apenas nas últimas décadas a escrita de Maria Firmina dos Reis tem recebido o reconhecimento que lhe é devido, graças ao trabalho incansável de pesquisadores nas áreas dos estudos de gênero e estudos afro-brasileiros. Destaco aqui o esforço do Grupo Literafro (www. 
letras.ufmg.br/literafro) e de outros estudos recentes, como o de Jessica Catharine B. de Carvalho (2018) e o de Rafael Balseiro Zin (2019).

Todos os trabalhos e iniciativas tiveram o mérito de conferir destaque à intelectual negra e, ao mesmo tempo, iluminaram os sentidos de seu romance mais importante, Úrsula, no âmbito do romantismo brasileiro. Mas por que perfilar a vida intelectual de Maria Firmina dos Reis? Porque a autora foi pioneira ao questionar, em diversos meios e de maneira jamais panfletária, o racismo estrutural à brasileira. E é a relação entre as particularidades do romance romântico firminiano, somadas às incursões pelo viés da "razão negra", conforme postula Achille Mbembe (2014), a preocupação das próximas páginas.

\section{A noção de literatura afro-brasileira e a escrita de Maria Firmina dos Reis}

A chamada literatura afro-brasileira surge a partir do reconhecimento das especificidades e lutas do ser negro no país. Octavio Ianni (1988) defende que tal literatura está situada dentro e fora da literatura nacional e vale-se dos mesmos gêneros, suportes e heranças. No entanto, resguarda as peculiaridades históricas e de pensamento resultantes de procedimentos específicos quando da elaboração textual.

A linhagem literária afro-brasileira - na qual se inserem os textos de Maria Firmina dos Reis - procura incidir diretamente nas orientações das seguintes instâncias, conforme pontua Eduardo de Assis Duarte (2011): a temática; a autoria; o ponto de vista; a linguagem e as imagens veiculadas pelos objetos artísticos. Existe uma voz autoral interna à afrodescendência, explícita ou não no discurso e que enuncia o universo deste coletivo; são abordados temas afro-brasileiros, africanos ou diaspóricos; há recorrentes construções linguísticas marcadas por uma afro-brasilidade no tom, ritmo, sintaxe ou sentido; há notório projeto de intervenção social por parte dos autores.

Do ponto de vista da temática, a literatura afro-brasileira procura abordar não só o sujeito afrodescendente, enquanto indivíduo, mas seu coletivo identitário, enquanto universo humano, social, cultural e artístico. Há inequívoco desejo de resgatar a história do povo negro, seja em África, seja na diáspora, passando pela denúncia da escravidão e de suas consequências, até chegar à discussão do lugar do negro na sociedade de classes. 
A temática ainda abrange as tradições culturais e religiosas trazidas para o Novo Mundo, destacando a riqueza de todo um imaginário conferido quase sempre à oralidade, segundo boa parte dos manuais de História. Destacam-se os dramas vividos pelos negros, o que implica o preconceito, a pobreza, a prosperidade, os dilemas sociais e subjetivos. Eduardo de Assis Duarte (2011) lembra-nos de que a adoção da temática negra não deve ser considerada isoladamente, e sim em sua interação com outros fatores, como autoria e ponto de vista.

A instância da autoria é das mais controversas, pois implica a consideração de fatores biográficos ou fenotípicos, com todas as dificuldades que daí decorrem. Duarte (2011) propõe entender a autoria não apenas como um dado "exterior" ao sujeito, mas como uma constante discursiva integrada à materialidade das formas e conteúdos das construções literárias. Isso porque a vertente literária em questão é composta majoritariamente por autores negros ou mulatos, cujos projetos estéticos se identificam com o universo cultural de seus irmãos de cor. Trata-se, pois, de uma produção repleta de elementos afrodescendentes, os quais convivem em constante tensão com elementos culturais hegemônicos na sociedade brasileira.

Por sua vez, a instância da autoria, no âmbito da literatura afro-brasileira, leva em consideração a relação entre escritura e experiência, que inúmeros autores negros fazem questão de destacar, seja enquanto compromisso identitário e comunitário, seja no tocante à sua própria formação de artista. Os traços autobiográficos marcam as páginas de inúmeros autores. Há, por vezes, o testemunho ou a "escrevivência" como operadores discursivos dessa linhagem literária. Conceição Evaristo (In ALEXANDRE, 2007) chama de escrevivência a escrita de um corpo, de uma condição, de uma experiência negra no Brasil. Os autores falam a partir da condição interna à negritude e, portanto, o negro é sujeito do discurso.

Logo, o trabalho com a linguagem é de fundamental relevância. Os autores "torcem" a língua portuguesa no intuito de melhor expressar o universo afro-brasileiro. Tenta-se a recuperação de referências culturais que fundamentam o imaginário afrodescendente muitas vezes subvertendo sentidos cristalizados, responsáveis por veicular estereótipos. No tocante às particularidades de ritmo e de entonação, são inúmeros os casos em que o texto expressa sonoridades outras, marcadas pelo rico imaginário afro-brasileiro. $\mathrm{O}$ discurso literário, pois, rompe com os contratos de fala e escrita ditados pelo discurso ocidentalizado e procura expressar 
decisiva reversão de valores. Tal capacidade de alteração significativa influi diretamente na conformação de público pressuposta por essa tradição literária.

Há nítido impulso à ação e ao gesto político capazes de levar à criação de outros espaços mediadores entre o texto e o receptor, desde publicações em periódicos, tal como fez Firmina, até eventos performáticos contemporâneos, como as rodas de poemas, os slams e os saraus. Os autores de que tratamos aqui, dentre eles Firmina, são dignos de mérito por estabelecerem uma série de debates na sociedade brasileira acerca da experiência negra, materializada em literatura e outros gêneros textuais. Logo, os textos por eles escritos ajudam a formatar novos modelos identitários: diferentes, portanto, daqueles calcados no etnocentrismo.

\section{A crítica da razão negra e projeto romântico}

Um dos motivos do suposto "esquecimento" da autora quando o assunto é a recepção crítica pode residir na diferença estabelecida pelo romance Úrsula ao ser comparado com outros exemplares de sua época. O texto da autora maranhense situa-se dentro e fora, em expressão de Octavio Ianni (1988), das linhas mestras da literatura brasileira à época. Dentro, porque se valeu dos suportes formais e temáticos evidentes no momento. E fora, porque procurou salientar as especificidades de uma narrativa marcadamente afrodescendente, o que se pode ver tanto no caráter representativo das personagens negras, quanto na postura do enunciador ao se colocar nada imparcial no texto. E é a partir desse "dentro e fora" do romantismo brasileiro que procuraremos entender o livro de Firmina, pois ele aponta para um posicionamento fundamental: a crítica da razão negra, entendendo-a conforme postula Achille Mbembe (2014, p. 25). De acordo com o filósofo camaronês, a razão negra diz respeito a "imagens do saber (...) paradigma da submissão e das moralidades da sua superação (...) um complexo psiconírico" que funciona como enorme "jaula" epistêmica solicitando desmonte. E este desmonte ocorre justamente por meio de representações do universo negro a partir de um ponto de vista interno a tal condição.

Não é novidade que o pensamento ocidentalizado, principalmente desde Hegel e os iluministas, tenha produzido a raça e o negro a partir de um "trabalho de efabulação" (MBEMBE, 2014, p. 38) calcado em práticas imagéticas e linguísticas, cujo resultado é a animalização, a diminuição, a bestialização do chamado diferente. Assim como Mbembe, 
consideramos que o ponto mais alto dessa construção discursiva talvez tenha sido Fenomenologia do espírito (1807), de Hegel. Em paralelo, o discurso ocidentalizado também inventou os arautos da humanidade: os europeus de pele clara. $\mathrm{O}$ resultado dessa dicotomia é percebido na economia do "dentro e fora" em que a literatura afro-brasileira se encontra no conjunto de nossas Letras. Enquanto lugar intervalar ou "jaula" que aprisiona o autor em determinadas constantes estéticas, o paradigma nacional da literatura abala-se no mesmo instante em que se renova por meio da aparição de novos elementos na série. A crítica epistemológica torna-se inevitável e o complexo psiconírico revela-se frágil diante de discursos que rejeitam a submissão a modelos e protoformas. $\mathrm{O}$ alvo inicial da literatura brasileira de autoria negra será o romantismo e os pilares de identidade, construídos sob o disfarce da nacionalidade. Em outras palavras, o desmonte das formas por meio das quais se manifestam a razão negra, cuja materialização se dá por meio da linguagem, "ecrã para a apreensão do sujeito, da sua vida e das condições de produção" (MBEMBE, 2014, p. 30 ), se dá por meio do ato de representação. Neste caso, o que se questiona é a produção do negro como "vínculo social de submissão e corpo de exploração" (MBEMBE, 2014, p. 40), ou seja, "material" exposto à vontade alheia e predisposto à geração de lucro. Dito de outra forma, o que se questiona é o aprisionamento representativo do negro enquanto mera peça da engrenagem produtiva e, portanto, não dotado de racionalidade. E é justamente no sentido de questionar a representação do sujeito negro como escravo, ou "peça", que o texto de Maria Firmina dos Reis ganha força e relevância, como veremos adiante.

Por ora, consideremos que romantismo brasileiro - pano de fundo contextual subjacente à época literária de Firmina - incumbiu-se de orquestrar os rumos da nação em processo de constituição. Coube à literatura, enquanto canal midiático de significativa amplitude naquele contexto, o papel de disseminar o ideal liberal e todos os seus estratagemas. Para tanto, a constituição da unidade nacional se fazia necessária, conforme podemos ver em textos como Iracema (1865), de José de Alencar. Neste livro, a integração nacional ocorreu de modo tenso entre as matrizes étnicas branca e indígena, ao passo que a afrodescendente foi desconsiderada. E assim o foi em quase todo o romantismo, à exceção de textos de autores abolicionistas.

No intuito de manter a "integração" nacional, era preciso que pares apaixonados superassem dificuldades inúmeras, conforme lembra Doris 
Sommer (2004). O caminho ascendente do casal apontava ou na direção da felicidade plena, ou na direção do trágico destino de quem ousasse a desconstruir as normas estabelecidas pela sociedade patriarcal vigente. Talvez por isso, parelhas interétnicos não tenham deixado descendentes oriundos de relação harmônica, já que a razão instituída avaliava a negritude como defeito a ser extirpado da sociedade. A alteridade aqui encontraria lugar apenas no discurso de comoção típico de fases mais adiantadas do romantismo, tendo Castro Alves como exemplo maior. Mesmo assim, o outro é tema, objeto literário, quando não "animal" digno de comoção, passível, portanto, de moldagem plástica ao discurso e, logo, de enclausuramento topográfico no âmbito da nação. Em outras palavras, no âmbito da nação, o negro é resultante do complexo psiconírico de produção da raça "entre o credível e o inacreditável, o maravilhoso e o factual", como aponta Achille Mbembe (2014, p. 38).

Por falar em nação, Benedict Anderson (1983) lembra-nos de que a nação é antes de tudo construção discursiva - assim como a produção da raça, acrescentamos, concordando com Mbembe. Por isso, ela precisa ser ritualizada, narrada, compartilhada em meios de largo alcance. Sem esse mecanismo, ela perde força e se esfacela, pois, por princípio, precisa forjar pontos comuns entre seus membros, quais sejam a identidade e o pertencimento. Estes, em seus turnos, são construídos por meio de entrecruzamentos discursivos, os quais amparam práticas sociais cotidianas. Trata-se de um processo de produção, de linguagem e de partilha. E é justamente nesses três âmbitos que o romance Úrsula estabelece a fratura que o coloca "dentro e fora" do romantismo - ao mesmo tempo em que estabelece outros pilares para a razão negra.

O romance reproduz, até determinado ponto, o ideal romântico ao ambientar-se num espaço natural vigoroso, cujas cores apontam para uma espécie de harmonia inata dos trópicos, paraíso para o desenvolvimento de jovens nações (liberais) latino-americanas. Tendo majoritariamente o campo como pano de fundo, mas sem se esquecer da cidade, até aí o texto segue a concepção literária defendida por Francisco Sotero dos Reis (1866, p. 4): “o fim da literatura é instruir deleitando", "tornar, por um trabalho tão proveitoso como agradável o homem melhor" (...), "pondo-lhe constantemente diante dos olhos o protótipo do belo, do grandioso, do sublime, do justo, do honesto" (REIS, 1866, p. 4). O comentário de Sotero dos Reis ilumina o sentido pedagógico da nação que se formara à época, pautada por dramas localizados numa burguesia- 
-pano-de-fundo para as transformações por que o país passava. E, claro, abordado por Firmina.

Por sua vez, a narrativa de Maria Firmina dos Reis problematiza a construção da nação. O escravizado e sua condição, o negro liberto e sem perspectivas, a diáspora, as inúmeras formas de violência, o cativeiro, a subjetividade do outro, "a jaula", enfim, para usar um termo de Achille Mbembe, tudo isso perturba os esquemas adotados pelos autores burgueses. A autora maranhense convoca personagens e histórias muitíssimo distintas daquelas que se tentava chamar de narrativa nacional brasileira. Ao falarmos dos dramas dos negros, há que se levar em conta os dramas também dos brancos, embora não tão aprisionados pela estrutura escravocrata e patriarcal, são, ao menos, em alguns casos, vitimados por ela.

Mergulhando na narrativa propriamente dita, temos, por um lado, o jovem escravizado Túlio; pai Antero; e a escrava Susana. Por outro lado, temos Tancredo, bacharel em direito; Úrsula, protagonista; e Fernando P., vilão. Essas personagens compõem dois universos distintos e em contato tenso a partir do qual a narrativa construirá suas tessituras.

Do primeiro grupo, já imaginamos os infortúnios. Porém, com relação ao segundo, vale conferir destaque ao posicionamento do livro, em que Tancredo é enganado pelo próprio pai, quando este se casara com Adelaide, pretendida pelo mais jovem certa vez. Tancredo descobre que a mulher estava a se apropriar das fortunas e benesses proporcionadas pelo patriarca. Mas, antes, a autora do livro prepara o terreno para, em meados da narrativa, construir a crítica a esse modelo de sociedade.

Talvez, ciente da amplitude de sua crítica e, ao mesmo tempo, do horizonte de expectativa que a aguardava (branco, masculino, cristão, burguês e liberal), Maria Firmina dos Reis tenha adotado um tom mais comedido ao advertir o público sobre suas intenções com o "mesquinho e humilde romance" (REIS, 2004, p. 13) que ela publicara. No prólogo, lemos: "não é a vaidade de adquirir nome que me cega, nem o amor próprio de autor. Sei que pouco vale este romance, porque escrito por uma mulher, e mulher brasileira, de educação acanhada e sem o trato e conversação dos homens ilustrados" (REIS, 2004, p. 13). Se, por um lado, tal atitude revela acanhamento por parte da artista, é justamente este acanhamento o salvo conduto necessário para fazer com que sua obra circulasse livremente num contexto permeado por adversidades de inúmeras ordens, como o machismo e o racismo.

Ponto para a escritora, que afasta a atenção de parte da crítica e da 
opinião pública imediatamente contrária a ela para focalizar o leitor comum, o qual se forma juntamente com a nação também por meio da literatura. Instruir via comunicação aqui significa repetir estratégias românticas - aquelas responsáveis pela atração de público, conforme defende com Doris Sommer (2004) - e rasurar o receituário temático hegemônico, por meio da dicção negra brasileira. Dito em outras palavras, rasurar os elementos fundamentais da nação, tal como elaborada pelo romantismo, por meio da reconfiguração da linguagem e da consequente ressignificação de estratégias e formas representativas, conforme se entende por meio da noção de "razão negra".

Nesta medida, tratar da razão negra, no âmbito de Úrsula, significa não só trazer à discussão o bom caráter do transplantado, temática tão em voga no romantismo brasileiro. Era preciso também - por dentro e por fora deste receituário de boas maneiras românticas - tematizar a escravidão, "fonte batismal da nossa modernidade" (MBEMBE, 2014, p. 31), e suas mazelas, como elementos constitutivos da nação brasileira. Mesmo que, para isso, a narrativa tivesse que recorrer ao tema do amor entre Tancredo e Úrsula, os quais são perseguidos por Fernando P., tio da jovem, como pano de fundo. Por trás da desventura do casal apaixonado, há lugar para narrativas e personagens outras, correspondentes a razões suplementares e não contempladas pelos textos fundadores do romance romântico brasileiro.

E é por meio dessas personagens secundárias que o livro de Firmina discute a escravidão e as situações em que se encontra o sujeito afro-brasileiro. As trajetórias de Túlio, Mãe Susana e Antero bem ilustram nosso argumento, pois exemplificam estratégias representativas da "razão negra".

Túlio, por exemplo, dará o tom diferencial. Apresentado no texto como "compassivo escravo" (REIS, 2004, p. 24), marcado pela "nobreza de um coração bem formado" (REIS, 2004, p. 22), a personagem não parece guardar mágoas da escravidão. Ao contrário, demonstra ser ela $o$ motivo da resiliência necessária para enfrentar a condição tão adversa. Mas é por meio do tom aparentemente cordial que Maria Firmina dos Reis denuncia a produção do negro como corpo de exploração e sustentáculo do empreendimento capitalista ocidentalizado.

Túlio posiciona-se criticamente diante da condição escrava, é verdade, e isso o faz lutar contra tal instituição sem perder de vista a expressão de seus sentimentos mais fraternos. Vale considerar que o texto 
confere voz ao oprimido, postura bem diferente do romantismo nacional, em que os enunciadores tomam quase totalmente o turno da palavra.

O narrador faz questão de remarcar o forte senso de justiça de Tulio, conferindo-lhe características positivas e, ao mesmo tempo, uma "nobreza de caráter" esperada aos heróis brancos, conforme receituário de boa parte das narrativas românticas. O horizonte de expectativa é alterado, uma vez que a personagem se afasta de representações correntes à época (cf. PROENÇA FILHO, 2004, p. 161-193.). A condição afrodescendente é, aqui, vetor positivo:

o sangue africano refervia-lhe nas veias; o mísero ligava-se à odiosa cadeia da escravidão; e embalde o sangue ardente que herdara de seus pais e que o nosso clima e a servidão não puderam resfriar, embalde dissemos - se revoltava; porque se lhe erguia como barreira - o poder do forte contra o fraco! (REIS, 2004, p. 22)

Observa-se que o livro recusa a inscrição de Túlio como personagem animalizada. Como não poderia deixar de ser, dadas as correntes estilísticas da época, o romance constrói dicotomias a partir das quais desenvolve a trama. $\mathrm{O}$ forte e o fraco estão ligados a categorias sociais demarcadas. Ele convoca, sim, a relação dominador $\mathrm{X}$ dominado, procedimento tipicamente romântico, mas também ilumina as cores inerentes a estes sujeitos. Branco e negro, respectivamente, são polos em constante tensão no romance. Outros polos antagônicos presentes no livro são: homem (Fernando P.) X mulher (Úrsula); riqueza (Fernando P.) X pobreza (Luisa B.); amado (Tancredo) X refutado (Fernando P.); liberdade (Tancredo) X cativeiro (Túlio); virtude (Túlio) X vício (Antero); retidão (Úrsula) X arrivismo (Adelaide); condição livre (Luisa B.) X condição cativa (Mãe Susana).

Tais exemplos ilustram nossa intenção de demonstrar a ampliação de leituras propostas por Maria Firmina dos Reis. A polissemia advinda desses pares rasura e alarga os limites dos pares oposicionais típicos do romantismo canônico brasileiro. Neste, encontramos de modo corrente o "esquema" entre o estrangeiro branco e conquistador e o nativo mestiço e dominado, como é possível perceber em O guarani (1857) e Iracema (1865), de José de Alencar, por exemplo. Nesses textos, o conflito direto assume o plano principal. Em outros casos, o elogio à bravura, de que fala Doris Sommer (2004) - e necessário nos romances fundacionais cede lugar a conflitos menos sangrentos, localizados nos planos social e simbólico, nos chamados romances urbanos - como A moreninha (1844), 
de Joaquim Manuel de Macedo; A viuvinha (1857), Lucíola (1862), Diva (1864) e Senhora (1875), de José de Alencar. Esses livros apontam para a conformação nacional a partir da miscigenação e da resiliência dos pares amorosos que conformarão a futura nação brasileira. Tais pares e conflitos do romantismo canônico esquecem-se do coletivo afrodescendente e projetam uma nação inverossímil. Se mestiça, é no máximo cabocla. Por outro lado, a proposta de Firmina escancara não só a presença desse coletivo, mas aponta contribuições e dilemas para uma nação que exclui, apaga, dilui o diferente. Em vez de conformar o destino do país através da miscigenação - artifício por meio do qual Alencar, por exemplo, parece resolver todos os conflitos - a autora maranhense deixa latejantes os problemas étnicos e, a nosso ver, já aponta para a não inserção do negro na sociedade de classes após a Abolição.

Úrsula interroga as fontes românticas brasileiras no que diz respeito à produção do negro. Ciente de que as imagens de negros predominantes em nossa literatura são pautadas em estereótipos, mesmo naqueles autores recheados de boa intenção, como Castro Alves, Maria Firmina dos Reis inscreve Tulio em outra ordem moral, agora assinalada pela nobreza de caráter. Como estratégia do romance romântico, a personagem Tulio cresce logo após salvar Tancredo, que pertence a uma família nobre, de um acidente ocorrido quando o jovem passeava a cavalo. Tulio carrega Tancredo nos braços, leva-o até a casa de Mãe Susana, cuida dele juntamente com Susana e Úrsula, por quem o jovem nobre irá se apaixonar.

Destaque para o fato de que, apesar das mazelas da escravidão, Tulio se conserva bom, a ponto de sentir "piedoso interesse, vendo esse homem [Tancredo] lançado por terra" (REIS, 2004, p. 22). Indiretamente, o texto critica a tese em voga à época de sua escrita de que o homem é produto do meio em que vive. E mais: desconstrói a máxima lockiana de que o homem nasce bom e a sociedade o corrompe. O romance ilumina justamente o caráter de Tulio para fazê-lo, à sua maneira, tão nobre quanto Tancredo, ou mais. Da mesma forma que aquele demonstra piedade ao salvar o nobre, Tulio demonstra gratidão pelo ato de seu futuro fiel amigo. "As almas generosas são sempre irmãs" (REIS, 2004, p. 26), arremata o texto. Note-se que o parâmetro de comparação é o negro e não o branco, atitude oposta àquela adotada pela razão ocidentalizada, da qual o romantismo brasileiro é exemplo. Neste ponto, o reconhecimento de Tancredo se dá justamente pelo exemplo do escravizado Tulio, cujos "sentimentos generosos, que Deus lhe implantou no coração, permaneciam intactos, e 
puros como a sua alma. Era infeliz, mas era virtuoso" (REIS, 2004, p. 23). Aliás, nem mesmo a escravidão foi capaz de abalar o coração e os bons sentimentos de Tulio. Eis aqui, em pleno romantismo, a defesa explícita de uma imagem positiva para uma personagem afrodescendente. $\mathrm{O}$ traçado construído para as personagens negras, segundo Firmina, portanto, perpassa a virtude de caráter e a infelicidade advinda da condição escrava.

A virtude e a infelicidade marcam também Mãe Susana: virtuosa por resistir às agruras da escravidão em terras brasileiras; e infeliz porque impotente nessa condição. E, ainda assim, ajudou a tantos e tantos de seus irmãos de sofrimento, como Túlio. Susana ganha relevo na narrativa quando ela enuncia o (provável) primeiro relato sobre o trânsito negreiro, realizado por uma personagem literária, nove anos antes do tão afamado "Navio Negreiro" (1869), de Castro Alves.

$\mathrm{O}$ trecho de maior contundência descreve o interior do navio. E, aqui, uma diferença fundamental em relação à versão castroalvina: enquanto Alves concentra atenções no convés, o relato de Mãe Susana focaliza não somente os porões, mas descreve também as condições do transporte e os dramas subjetivos dos viajantes. Logo, chama a atenção o lugar enunciativo afro-identificado tanto da autora quanto da personagem.

Meteram-me a mim e a mais trezentos companheiros de infortúnio e de cativeiro no estreito e infecto porão de um navio. Trinta dias de cruéis tormentos e de falta absoluta de tudo quanto é mais necessário à vida passamos nessa sepultura até que abordamos as praias brasileiras. Para caber a mercadoria humana no porão fomos amarrados em pé e para que não houvesse receio de revolta, acorrentados como animais ferozes de nossas matas, que se levam para recreios dos potentados da Europa. Davam-nos a água imunda, podre e dada com mesquinhez, a comida má e ainda mais porca: vimos morrer ao nosso lado muitos companheiros à falta de ar, de alimento e de água. É horrível lembrar que criaturas humanas tratem a seus semelhantes assim e que não lhes doa a consciência de levá-los à sepultura asfixiados e famintos [...]. Nos dois últimos dias, não houve mais alimento. Os mais insofridos entraram a vozear. Grande Deus! Da escotilha, lançaram sobre nós água e breu fervendo, que escaldou-nos e veio a dar a morte aos cabeças do motim (REIS, 2004, p. 117).

A razão negra no trecho é estabelecida por um discurso interno, testemunhal da migração forçada. Mesmo se tratando de ilação, o relato de mãe Susana procura suplementar os arquivos da história. Os verbos de ação presentes no trecho, por sua vez, denunciam os sentidos de identi- 
dade e de memória pessoal e coletiva da narradora-personagem em relação às cenas vivenciadas no trânsito pelo Atlântico. $\mathrm{O}$ interior do navio transforma-se em lugar de resistência à dominação.

Adiante, Susana demonstra consciência do momento histórico vivido em seu território. Mesmo em uma África varrida por conflitos de inúmeras ordens, ela declara possuir felicidade em sua terra de origem, pois ali estava em liberdade na companhia de seu esposo e filha. Mais uma vez, o romance, com toda sutileza, recusa fabulações acerca da África. Tal continente é vasto e diverso, povoado por comunidades organizadas por meio de lógicas próprias. E mesmo que o romance, por vezes, idealize o território africano, o que nos fica é o comportamento enunciativo de Susana e a experiência por ela vivida na viagem transatlântica e no cativeiro, singulares no âmbito da narrativa romântica brasileira.

Prova disso é a cena adiante. Em pleno período de colheita em sua terra natal, Susana estava a campear quando foi surpreendida por dois homens, que a amarraram e a levaram como prisioneira. Em vão, a pobre suplicou por liberdade: "os bárbaros sorriam-se das minhas lágrimas, e olhavam-se sem compaixão" (REIS, 2004, p. 116), afirma em seu relato. Vale destacar a escolha pelo signo "bárbaro" no discurso de Susana. Se, numa perspectiva eurocêntrica, os afrodescendentes foram tratados como bárbaros, o contradiscurso da personagem questiona a versão hegemônica ao relativizar a autoria dos atos de barbárie. Até porque a fala da personagem destaca a natureza da sociedade deixada por ela. Havia plantações, organização política e, portanto, pensamento lógico e técnica no sentido mais científico possível. Desconstrói-se, assim, a noção de uma África bárbara, homogênea, incivilizada. No texto de Firmina, a barbárie é associada ao europeu, ao passo que o africano é o civilizado.

Hayden White (1994) chama-nos a atenção para o caráter literário do discurso historiográfico. À antípoda, o relato de Mãe Susana ilumina a pertinência histórica do discurso literário ao valer-se da verossimilhança como estratégia narrativa e argumentativa, ou seja, o mesmo estratagema apontado por White. A natureza do relato ajuda a compor ainda a comoção e identificação com o sofrimento do oprimido, ao passo que vai paulatinamente desconstruindo simpatias com os "civilizadores", isto é, estabelecendo outras bases para a razão negra. Úrsula aponta para a necessidade de rasura dos arquivos literário e histórico do período a que faz menção.

Maria Firmina denuncia a destruição causada pela condição escra- 
va, "a fonte batismal da modernidade", como defende Achille Mbembe (2014). Para isso, coloca em cena a personagem Antero. Decrépito, com autoestima abalada e dado ao alcoolismo, a personagem opera como metonímia da condição senil negra na sociedade escravocrata. Corpo reduzido à máquina na engrenagem produtiva, "Antero era um escravo velho, que guardava a casa" (REIS, 2004, p. 205). Entendido como tal, o cativo em idade avançada era destinado a tarefas sem importância ou abandonado nas cidades, pois já não estava em plenas condições laborais. Antero trabalhava como carcereiro, atividade considerada "menor" na economia da sociedade da época, até mesmo entre os cativos. Herdeiro da lógica produtiva das plantações, pode-se dizer que Antero se enquadra na afirmação de Mbembe (2014, p. 41) sobre a construção da ordem e da vigília escravocrata: o negro-vigia "se sociabiliza no ódio dos outros, sobretudo dos outros negros".

No jogo entre oposições, as quais rasuram as bases do romantismo nacional, Antero cumpre no livro lugar diametralmente oposto à feição elevada de Túlio. As duas faces - degeneração e caráter - fazem parte da conformação do país, não havendo aqui possibilidade de interpretação entre branco bom em oposição ao negro mau. Antero é bom $e$ mau. Vítima $e$ algoz. Objeto $e$ sujeito da escravização. Símbolo de um enorme coletivo que vive às margens do sistema que ajuda a construir.

Em nossa leitura, Antero fecha o conjunto de personagens negras responsáveis pelo desvio da atenção do leitor em relação ao plano principal e tipicamente romântico da narrativa. $\mathrm{O}$ triângulo amoroso formado por personagens brancas - Tancredo, Úrsula e Fernando P. - paulatinamente cede lugar a outro triângulo, formado por Tulio, Mãe Susana e Antero. Embora Firmina deixe claro o propósito romântico de seu texto, a autora demonstra igualmente a proposta de reescritura da razão negra interna, subjetiva. Se o amor é o elemento motriz do romantismo nacional, tal sentimento solicita do leitor certo senso de solidariedade para avaliar as atitudes (quaisquer que sejam) entre os menos favorecidos.

A solidariedade é demonstrada pelas relações estabelecidas entre as personagens negras, ao contrário da dicotomia amor e ódio que move a tríade branca. Capturado e preso pelo Comendador Fernando P., Túlio fica sob a responsabilidade de Antero. Aquele, percebendo neste o vício, deu dinheiro para que pudesse comprar cachaça. Túlio retira-lhe as chaves, foge e, curiosamente, arma cenário para que Antero pudesse se esquivar da ira do comendador Fernando P.: 
[Antero] não pode mais falar, e caiu em profundo sono, entrecortado só por uma respiração forte e estrepitosa. Então Túlio arrastou-o pelas pernas, e o foi levando até um tronco, que se unia à parede, e lá depois de o ter bem seguro, tirou-lhe da algibeira a chave da prisão e saiu (REIS, 2004, p. 210).

Reiterando sua nobreza de caráter, Túlio previra a provável explosão de cólera do comendador quando de volta de sua tentativa de emboscar Tancredo. Ao encontrar Antero embriagado e amarrado no tronco, a cela aberta e a ausência do prisioneiro, o comendador provavelmente acreditaria que se dera uma luta entre ele e o fugitivo, e que "aquele, velho e sem forças, fora subjugado e preso", de modo que apenas "vira a fuga [de Tulio] sem poder sequer opor-lhe a menor resistência" (REIS, 2004, p. 201). Tulio demonstrou, por fim, solidariedade em relação a Antero, o que confirma a elevação de caráter daquele e o compromisso com o seu irmão de infortúnio.

\section{Considerações finais}

Úrsula não é apenas o provável primeiro romance afro-brasileiro de que se tem notícia. É também o provável primeiro romance comprometido com a tematização do negro a partir de uma perspectiva interna de construção da razão negra. O livro utiliza-se de procedimentos literários típicos do romantismo e faz questão de subvertê-los. Úrsula abre caminhos. Temas quase obrigatórios na linhagem literária afro-brasileira, como o trauma da escravidão e suas consequências, bem como a manifestação da subjetividade do ser negro serão em grande medida encontrados em outros romances afro-brasileiros, como Vencidos e degenerados, de Nascimento Moraes; Becos da memória, de Conceição Evaristo; e Um defeito de cor, de Ana Maria Gonçalves, dentre muitos outros. O romance de Firmina inaugura, pois, uma série de narrativas de autoria negra comprometidas com a retomada do tema da escravização e com a possibilidade narrativa do negro para além dessa temática. E, ao fazê-lo, demarca a razão negra como aspecto diferencial do nosso romantismo e, por que não, de nossa literatura. 


\section{REFERÊNCIAS}

ANDERSON, Benedict. Imagined communities: reflections on the origin and spread of nationalism, London: Verso, 1983.

CARVALHO, Jessica Catharine Barbosa de. Literatura e atitudes políticas: olhares sobre o feminino e antiescravismo na obra de Maria Firmina dos Reis. Teresina: PPGL/UFPI, 2018 (Dissertação de mestrado).

DUARTE, Eduardo de Assis. Maria Firmina dos Reis e os primórdios da ficção afro-brasileira. In: REIS, Maria Firmina dos. Úrsula. Florianópolis: Editora Mulheres; Belo Horizonte: PUC Minas, 2004. "Posfácio".

DUARTE, Eduardo de Assis. Por um conceito de literatura afro-brasileira. In: DUARTE, Eduardo de Assis; FONSECA, Maria Nazareth Soares (Org.). Literatura e afrodescendência no Brasil: antologia crítica. Belo Horizonte: Editora UFMG, 2011, v. 4, p. 375-403.

EVARISTO, Conceição. Da grafia-desenho de minha mãe, um dos lugares de nascimento de minha escrita. In: ALEXANDRE, Marcos Antônio (Org.). Representações performáticas brasileiras: teorias, práticas e suas interfaces. Belo Horizonte: Mazza, 2007.

IANNI, Octavio. Literatura e consciência. In: Revista do Instituto de Estudos Brasileiros. Edição Comemorativa do Centenário da Abolição da Escravatura, n. 28. São Paulo: USP, 1988. p. 91-99.

LOBO, Luiza. Auto-retrato de uma pioneira abolicionista. In: LOBO, Luiza. Crítica sem juízo. Rio de Janeiro: Francisco Alves, 1993. p. 222-238.

MBEMBE, Achille. Crítica da razão negra. Lisboa: Antigona, 2014.

MORAIS FILHO, José Nascimento. Maria Firmina: fragmentos de uma vida. São Luís: COCSN, 1975.

MOTT, Maria Lúcia de Barros. Submissão e resistência: a mulher na luta contra a escravidão. São Paulo: Contexto, 1988.

MUZART, Zahidé Lupinacci (Org). Escritoras Brasileiras do século XIX. Florianópolis: Ed. Mulheres, 1999.

OLIVEIRA, Luiz Henrique Silva de. Poéticas negras. Belo Horizonte: Nandyala, 2007.

PROENÇA FILHO, Domício. A trajetória do negro na literatura brasileira: de objeto a sujeito. Estudos Avançados, n. 50. vol. 18, p. 161-193, 2004.

REIS, Francisco Sotero dos. Curso de literatura portuguesa e brasileira. São Luis: Tip. de B. de Mattos, 1866. 
SOMMER, Doris. Ficções de fundação: os romances nacionais da América Latina. Belo Horizonte: Editora UFMG, 2004.

WHITE, Hayden. Trópicos do discurso: ensaios sobre a crítica da cultura. Trad. Alípio Correia de Franca Neto. São Paulo: Editora da Universidade de São Paulo, 1994.

ZIN, Rafael Balseiro. Maria Firmina dos Reis: trajetória intelectual de uma escritora afrodescendente no Brasil oitocentista. São Paulo: Aetia Editorial, 2019.

Recebido em: 30/04/2019

Aceito em: 30/09/2019 